\title{
Environmental Health Surveillance: A Critical Function of Public Health Laboratories
}

\author{
Sylvia Checkley*1, 2, Sumana Fathima ${ }^{2}$, Norman Neumann ${ }^{2,3}$ and Shamir Mukhi ${ }^{4,2}$ \\ ${ }^{1}$ Ecosystem and Public Health, University of Calgary, Calgary, AB, Canada; ${ }^{2}$ Provincial Laboratory for Public Health, Calgary, AB, \\ Canada; ${ }^{3}$ School of Public Health, University of Alberta, Edmonton, AB, Canada; ${ }^{4}$ Canadian Network for Public Health Intelligence, \\ National Microbiology Laboratory, Winnipeg, MB, Canada
}

\section{Objective}

The objectives of this environmental health surveillance system were to provide a robust system for monitoring of water quality trends, and information to be used for mitigation of potential health problems, resource planning, risk analyses and decision making.

\section{Introduction}

Canada experienced 92 waterborne diseases outbreaks between 1975 and $2001^{1}$. In addition, at any one time about 1500 communities in Canada are unable to use their drinking water. The source of exposure in disease outbreaks is often not known, so the true disease burden attributable to water related exposure may be much higher. Researchers have investigated risk factors for waterborne disease ${ }^{2,3}$. However, providing acces to surveiallance tools of use by frontline staff in the field as well as by surveillance professionals was key to making this type of system successful.

\section{Methods}

This system involved drinking water and recreational water samples submitted to the provincial laboratory for public health in Alberta, Canada. A web-based system was developed for real-time integration of laboratory data for routine use through a secure data interface. Data was classified by the tool to make interpretation explicit. This tool was available for use by Environmental Health Officers, widespread in the field including trends over time within specific locations. Ongoing support was available for training and specific questions. Routine reporting was also developed for a broad range of stakeholders through active feedback. Reporting was also responsive to user needs, for example, 2013 floods in southern Alberta.

\section{Results}

Baselines have been created. Weekly and seasonal trends are described. Reporting was automated. Information was packaged for stakeholders in the field and at the policy making level.

\section{Conclusions}

Routine surveillance can be useful at multiple levels from field application to regional emergencies. This was demonstrated through examples involving drinking water and recreational water, routinely and in emergency situations.

\section{Keywords}

Environmental Public Health Surveillance; Drinking water; Waterborne disease

\section{Acknowledgments}

Thank you to the all staff at the Alberta Provincial Laboratory for Public Health who make this work possible.

\section{References}

1. Eggerston L. Investigative report: 1766 boil-water advisories now in place across Canada CMAJ 2008178 (10): 1261.

2. Jones AQ, Majowicz SE, Edge VL, Thomas MK, MacDougall L, Fyfe M, Atashband S, Kovacs SJ. Drinking water consumption patterns in British Columbia: an investigation of associations with demographic factors and acute gastrointestinal illness. Sci Tot Environ 2007 388:54-65.

3. Thomas MK, Charron DF, Waltner-Toews D, Schuster C, Maarouf AR, Holt JD. A role of high-impact weather events in waterborne disease outbreaks in Canada, 1975-2001. Int J Environ Health Res 2006 16(3):167-180.

\section{*Sylvia Checkley}

E-mail: slcheckl@ucalgary.ca 